\title{
Decrease of Nitric Oxide End-products during Coronary Circulation Reflects Elevated Basal Coronary Artery Tone in Patients with Vasospastic Angina
}

\author{
Tomoyuki Hori, MD, Taku MATSUBARA, MD, Takaharu ISHIBASHI, ${ }^{1} \mathrm{MD}$, \\ Masaru Yamazoe, MD, Toru IDA, MD, Kotaro HigUCHI, MD, \\ Minoru TAKEMOTO, MD, Sachie OCHIAI, MD, Yusuke TAMURA, MD, \\ Yoshifusa AIZAwA, MD, and Matomo NishIO, ${ }^{1} \mathrm{MD}$
}

\begin{abstract}
SUMMARY
The aim of this study was to investigate the role of nitric oxide (NO) in the coronary circulation and its relation to basal coronary artery tone in patients with vasospastic angina (VSA). We evaluated the level of nitric oxide end-products (NOx; nitrite + nitrate) in coronary circulation blood using an HPLC-Griess system for nine patients with VSA and nine control patients. All of the patients with VSA experienced focal spasm in the proximal to middle segments of the left anterior descending coronary artery (LAD) in response to intracoronary injection of ergonovine maleate. The luminal diameter of the coronary artery was measured in each patient by quantitative coronary arteriography. Blood samples for NOx measurement were obtained from the coronary sinus $\left(\mathrm{NOx}^{\mathrm{V}}\right)$ and the ostium of the left coronary artery $\left(\mathrm{NOx}^{\mathrm{A}}\right)$. The NOx difference, calculated from the coronary venous-arterial difference in NOx, was close to zero for the control patients whereas it was clearly negative for the patients with VSA. In addition, the NOx difference in the patients with VSA showed a negative correlation with basal coronary artery tone $(r=-0.91, p<0.01)$ and a positive correlation with the dose of ergonovine required for spasm provocation $(r=0.77, p<0.05)$. These results indicate that increased basal coronary artery tone and higher susceptibility to ergonovine in patients with VSA would be a consequence of coronary endothelial dysfunction as is indicated by NOx. (Jpn Heart J 2000; 41: 583-595)
\end{abstract}

Key words: Nitric oxide, Coronary circulation, Vasospasm, Ergonovine maleate

THE endothelium modulates coronary vascular tone by releasing endotheliumderived relaxing and constricting substances. ${ }^{1-3)}$ The endothelium-derived relaxing factor has been identified as nitric oxide (NO) synthesized in endothelial cells

From the First Department of Internal Medicine, Niigata University School of Medicine, Niigata, and ${ }^{1}$ Department of Pharmacology, Kanazawa Medical University, Ishikawa, Japan.

Address for correspondence: Tomoyuki Hori, MD, First Department of Internal Medicine, Niigata University School of Medicine, 1-754 Asahi-machi-dori, Niigata, Niigata 951-8510, Japan.

Received for publication April 21, 2000.

Revised and accepted May 30, 2000. 
from L-arginine. ${ }^{4,5)}$ The importance of endothelial NO has been recently shown in maintaining basal coronary tone in animals and humans, ${ }^{6-9)}$ supported by the effects of intracoronary $\mathrm{N}^{\mathrm{G}}$-monomethyl-L-arginine (L-NMMA), an inhibitor of NO synthesis, on basal coronary artery response. ${ }^{89}$ (9) Quyyumi, et al..$^{9)}$ investigated the effects of intracoronary infusion of L-NMMA in patients with normal coronary arteriograms and suggested endothelial NO contributed significantly to the resting coronary artery tone.

In patients with vasospastic angina (VSA), basal coronary artery tone is elevated at the spastic site and plays an important role in the pathophysiological conditions. ${ }^{10-13)}$ Kugiyama, et al. ${ }^{14)}$ recently reported that decreased release of NO contributes to the increased basal tone at the spastic site in the spasm artery of patients with coronary spastic angina. However, Egashira, et al. ${ }^{15}$ ) demonstrated that the basal release of NO may not be reduced at the spastic site in patients with variant angina. Thus, these human studies using L-NMMA have yielded conflicting results and the reason why basal coronary artery tone is elevated in patients with VSA remains to be clarified. In the present study, on the hypothesis that the plasma level of NO may relate to basal coronary artery tone in patients with VSA, we examined the level of NO end-products (NOx; nitrite + nitrate) in the coronary circulation.

\section{METHOdS}

Study Patients: Nine control patients and nine patients with VSA, in whom focal spasm was provoked in the left anterior descending coronary artery (LAD) during diagnostic cardiac catheterization (Table I), were examined. The VSA patients (mean age, 57 years; range, 41 to 74 years; 9 men) had typical episodes of chest pain at rest and experienced coronary artery spasm in response to intracoronary injection of ergonovine maleate. No patients had significant organic stenosis $(\geq 50 \%$ reduction in luminal diameter) angiographically. Coronary spasm was provoked during angiography in the proximal to middle segments of the LAD. Patients with diffuse spasms or spasm in the peripheral segment of the LAD were excluded. The control patients (mean age, 62 years; range, 49 to 72 years; 6 men) had atypical chest pain but spasm was not provoked by intracoronary ergonovine maleate. They had angiographically normal or nearly normal coronary arteries. All patients had no history of myocardial infarction, valvular heart disease or congenital heart disease. Written informed consent was obtained from each patient before cardiac catheterization. The coronary risk factors: hypertension, hypercholesterolemia 
Table I. Clinical and Angiographic Characteristics of Study Patients

\begin{tabular}{|c|c|c|c|c|c|c|c|}
\hline \multirow[b]{2}{*}{$\begin{array}{c}\text { Case } \\
\text { no }\end{array}$} & \multirow[b]{2}{*}{$\begin{array}{c}\text { Age/Sex } \\
\text { (yr) }\end{array}$} & \multirow[b]{2}{*}{ HT } & \multirow[b]{2}{*}{$\mathrm{HC}$} & \multirow[b]{2}{*}{$\mathrm{DM}$} & \multirow[b]{2}{*}{ Smoking } & \multicolumn{2}{|c|}{ Coronary arteriographic findings at spastic site } \\
\hline & & & & & & Baseline diameter (mm) & Diameter after ISDN (mm) (\% DS) \\
\hline \multicolumn{8}{|c|}{ Control patients } \\
\hline 1 & $64 / \mathrm{M}$ & + & - & - & + & 1.89 & $2.35(26.7)$ \\
\hline 2 & 49 / F & - & - & - & - & 1.87 & $1.98(7.3)$ \\
\hline 3 & $51 / \mathrm{M}$ & + & - & - & - & 3.16 & $3.28(22.8)$ \\
\hline 4 & $72 / \mathrm{M}$ & - & - & - & - & 2.38 & $2.46(18.4)$ \\
\hline 5 & $65 / \mathrm{M}$ & - & - & - & + & 2.37 & $2.48(13.6)$ \\
\hline 6 & $71 / \mathrm{F}$ & + & + & - & - & 2.34 & $3.24(14.1)$ \\
\hline 7 & $66 / \mathrm{F}$ & - & - & - & + & 2.19 & $2.49(10.1)$ \\
\hline 8 & $55 / \mathrm{M}$ & - & - & - & + & 2.68 & $3.26(9.1)$ \\
\hline 9 & $72 / \mathrm{M}$ & + & + & - & + & 3.39 & $3.80(17.8)$ \\
\hline \multicolumn{8}{|c|}{ Patients with vasospastic angina } \\
\hline 10 & $67 / \mathrm{M}$ & + & + & - & + & 1.08 & $1.77(40.1)$ \\
\hline 11 & $47 / \mathrm{M}$ & - & - & - & + & 1.89 & $3.25(0.6)$ \\
\hline 12 & $41 / \mathrm{M}$ & + & + & - & + & 1.34 & $1.66(40.6)$ \\
\hline 13 & $57 / \mathrm{M}$ & - & - & - & + & 2.71 & $4.42(15.4)$ \\
\hline 14 & $48 / \mathrm{M}$ & - & - & + & + & 1.35 & $1.53(31.4)$ \\
\hline 15 & 74 / M & + & + & - & - & 0.92 & $1.15(39.3)$ \\
\hline 16 & $59 / \mathrm{M}$ & - & - & - & + & 1.39 & $1.96(35.4)$ \\
\hline 17 & $56 / \mathrm{M}$ & - & - & - & + & 2.33 & $3.33(8.8)$ \\
\hline 18 & $66 / M$ & - & - & - & + & 1.92 & $2.53(30.0)$ \\
\hline
\end{tabular}

Diameters in control patients were measured at corresponding site to spasm of patients with vasospastic angina. $\mathrm{DM}=$ diabetes mellitus; $\mathrm{F}=$ female; $\mathrm{HC}=$ hypercholesterolemia; $\mathrm{HT}=$ hypertension; ISDN=isosorbide dinitrate; $\mathrm{M}=$ male; $\% \mathrm{DS}=$ percentage diameter stenosis; +, yes; - , no.

(serum total cholesterol $>220 \mathrm{mg} / \mathrm{d} l$ ), diabetes mellitus and smoking were assessed for the two groups and there was no significant difference in the risk factor profile between the two groups (Table I).

Study protocol: Anti-anginal drugs were discontinued at least $48 \mathrm{~h}$ before cardiac catheterization. Although the use of sublingual nitroglycerin was to be permitted if needed, none of the patients used it in the $6 \mathrm{~h}$ before catheterization. Coronary arteriography was performed using Judkins technique as described previously. ${ }^{16,17)}$ Coronary arteriograms were recorded using a Philips cineangiography system (Integris H3000). The distances from the X-ray focus to the patient, and that from the patient to the image intensifier, were kept constant during the study. After the baseline coronary arteriography was recorded, ergonovine was infused at 10 $\mu \mathrm{g} /$ min until vasospasm was provoked or until the maximal dose of 50 $\mu \mathrm{g}$ had been given. In this study, coronary spasm was defined as total or 
subtotal occlusion of the epicardial coronary arteries associated with signs of myocardial ischemia such as chest pain and ischemic ST segment changes. When chest pain or significant ST segment changes occurred, coronary angiography was performed immediately. If coronary artery spasm was confirmed, isosorbide dinitrate (ISDN) was administered into the left coronary artery until the coronary spasm was relieved. The control patients routinely received an intracoronary injection of ISDN (2 $\mathrm{mg}$ ) to evaluate the basal coronary tone, and the effect of the ISDN was compared with that observed for the VSA patients. Heart rate, arterial pressure and a 12-lead electrocardiogram were monitored continuously.

Quantitative coronary angiography: Quantitative assessment of the luminal diameter of the coronary artery was performed using a computer-assisted quantitative cardiac analyzer, (CAM-1000, Nishimoto Sangyo Inc., Osaka, Japan). The luminal diameter was analyzed in the right anterior oblique position at end-diastole. For the VSA patients, we measured the luminal diameter of the LAD in which the focal spasm was provoked (spasm site). For the control patients, the LAD site corresponding to the spasm site of VSA patients was measured, and one or two branch points were determined to allow assessment of serial changes in the diameter at the same arterial site in response to ISDN. In addition, the luminal diameter was measured at the proximal and distal segments of the LAD and left circumflex artery (LCx) in both groups. The luminal diameter of the LAD was measured at the artery's origin (proximal) and at the point half the distance from the first major septal branch to the apex of the heart (distal). The diameter of the LCx was also measured at the artery's origin (proximal) and at the origin of the posterior lateral branch (distal). The size of a Judkins catheter was used for calibrating the arterial diameter in millimeters.

The basal coronary artery tone was calculated as follows,

Basal coronary artery tone $(\%)=$

(Diameter after ISDN-Baseline coronary artery diameter) $\times 100 /$ Baseline coronary artery diameter

Measurement of nitrite $\left(\mathrm{NO}_{2}^{-}\right)$and nitrate $\left(\mathrm{NO}_{3}^{-}\right)$in blood: Blood samples were obtained from the coronary sinus and the ostium of the left coronary artery. These samples were immediately heparinized $(20 \mathrm{U} / \mathrm{ml}$, final concentration) and centrifuged $\left(3,000 \mathrm{rpm}\right.$ at $4^{\circ} \mathrm{C}$ for $\left.5 \mathrm{~min}\right)$. The plasma was mixed with methanol $(1: 1)$ and centrifuged at $10,000 \times \mathrm{g}$ at $4{ }^{\circ} \mathrm{C}$ for $10 \mathrm{~min}$ to remove the protein. The supernatant was stored at $-80^{\circ} \mathrm{C}$ until analysed. $\mathrm{NO}_{2}{ }^{-}$and $\mathrm{NO}_{3}{ }^{-}$in the sample $(10 \mu l)$ were separated and quantified using an HPLC-Griess system (ENO-10, EICOM, Kyoto, 
Japan), as detailed elsewhere.$^{18,19)}$ The detection limit of the system was $0.1 \mu \mathrm{M}$ with a loading volume of $10 \mu \mathrm{l}$. A low concentration of heparin $\left(20 \mathrm{U} / \mathrm{ml}\right.$ ) had no appreciable effect on the quantification of $\mathrm{NO}_{2}^{-}$and $\mathrm{NO}_{3}{ }^{-}{ }^{20)}$ The $\mathrm{NOx}\left(\mathrm{NO}_{2}{ }^{-}\right.$and $\left.\mathrm{NO}_{3}{ }^{-}\right)$difference was calculated from the NOx level in the arterial blood collected from the ostium of the left coronary artery $\left(\mathrm{NOx}^{\mathrm{A}}\right)$ and that of the venous blood collected at the coronary sinus $\left(\mathrm{NOx}^{\mathrm{V}}\right)$ as follows:

NOx difference $=\mathrm{NOx}^{\mathrm{V}}-\mathrm{NOx}^{\mathrm{A}}$

Statistical analysis: All data are expressed as the mean \pm SEM. An unpaired $t$-test was used to compare the results for the two groups. Correlations between basal artery coronary tone and NOx difference, and between the ergonovine dose and the NOx difference were tested by linear regression analysis. A $p$ value of less than 0.05 was considered statistically significant.

\section{Results}

Coronary artery diameter at baseline and after ISDN: The baseline coronary artery diameters and the diameters after injection of ISDN are shown in Table II. Mean baseline coronary artery diameters of the proximal and distal coronary segments were not statistically different between the two groups. Only baseline coronary diameter at the spastic site in the VSA patients was significantly smaller than that of the corresponding site in the control patients $(1.66 \pm 0.20$ vs $2.47 \pm 0.17 \mathrm{~mm}, p<0.01)$. After

Table II. Coronary Artery Diameter in the Baseline Angiogram and after Isosorbide Dinitrate (ISDN) in Study Patients

\begin{tabular}{lcccc}
\hline & \multicolumn{2}{c}{ Baseline diameter $(\mathrm{mm})$} & \multicolumn{2}{c}{ Diameter after ISDN $(\mathrm{mm})$} \\
\cline { 2 - 5 } & $\begin{array}{c}\text { Control } \\
\text { patients }\end{array}$ & VSA patients & $\begin{array}{c}\text { Control } \\
\text { patients }\end{array}$ & VSA patients \\
& & & & \\
LAD & $3.18 \pm 0.26$ & $2.91 \pm 0.28$ & $3.55 \pm 0.32$ & $3.50 \pm 0.35$ \\
$\quad$ Proximal & $2.47 \pm 0.17$ & $1.66 \pm 0.20^{* *}$ & $2.82 \pm 0.20$ & $2.40 \pm 0.36$ \\
Spastic / Corresponding & $1.57 \pm 0.09$ & $1.88 \pm 0.16$ & $1.92 \pm 0.09$ & $2.55 \pm 0.29$ \\
Distal & & & & \\
LCx & & & $3.29 \pm 0.33$ & $3.01 \pm 0.29$ \\
Proximal & $2.73 \pm 0.30$ & $2.48 \pm 0.28$ & $2.58 \pm 0.26$ & $2.43 \pm 0.32$ \\
Distal & $2.06 \pm 0.24$ & $1.72 \pm 0.23$ & 26 \\
\hline
\end{tabular}

${ }^{* *} p<0.01$ compared with the control patients. Spastic, focal spasm site in VSA patients; Corresponding, corresponding site in control patients; $\mathrm{LAD}=$ left anterior descending coronary artery; $\mathrm{LCx}=$ left circumflex coronary artery; VSA=vasospastic angina. Values are expressed as mean + SEM. 
Table III. Basal Coronary Artery Tone in Study Patients

\begin{tabular}{lcc}
\hline & \multicolumn{2}{c}{$\%$ Dilatation after isosorbide dinitrate (ISDN) } \\
\cline { 2 - 3 } & Control patients & VSA patients \\
LAD & & \\
Proximal & $12 \pm 2$ & $20 \pm 5$ \\
Spastic / Corresponding & $14 \pm 4$ & $42 \pm 7 * *$ \\
Distal & $23 \pm 4$ & $37 \pm 11$ \\
LCx & & \\
Proximal & $22 \pm 3$ & $24 \pm 6$ \\
Distal & $27 \pm 6$ & $45 \pm 12$ \\
\hline
\end{tabular}

${ }^{* *} p<0.01$ compared with the control patients. Values are expressed as mean + SEM. Spastic, focal spasm site in VSA patients; Corresponding, corresponding site in control patients; $\mathrm{LAD}=$ left anterior descending coronary artery; $\mathrm{LCX}=\mathrm{left}$ circumflex coronary artery; VSA= vasospastic angina.

Table IV. Plasma NO End-product Levels, Basal Coronary Artery Tone and the Dose of Ergonovine Required for Spasm Provocation in Patients with Vasospastic Angina

\begin{tabular}{|c|c|c|c|c|c|c|c|c|}
\hline \multirow{2}{*}{$\begin{array}{c}\text { Case } \\
\text { no }\end{array}$} & \multicolumn{3}{|c|}{$\begin{array}{l}\text { NOx level in blood from the level } \\
\text { in Blood from the Ostium of the left } \\
\text { coronary artery }\end{array}$} & \multicolumn{3}{|c|}{$\begin{array}{l}\text { NOx level in blood from } \\
\text { the coronary Sinus }\end{array}$} & \multirow{2}{*}{$\begin{array}{c}\text { NOx } \\
\text { difference } \\
\quad(\mu \mathrm{M})\end{array}$} & \multirow{2}{*}{$\begin{array}{l}\text { Ergonovine } \\
\text { dose } \\
\quad(\mu \mathrm{g})\end{array}$} \\
\hline & $\begin{array}{l}\mathrm{NO}_{2}^{-} \\
(\mu \mathrm{M})\end{array}$ & $\begin{array}{l}\mathrm{NO}_{3}^{-} \\
(\mu \mathrm{M})\end{array}$ & $\begin{array}{l}\mathrm{NOx}^{\mathrm{A}} \\
(\mu \mathrm{M})\end{array}$ & $\begin{array}{l}\mathrm{NO}_{2}^{-} \\
(\mu \mathrm{M})\end{array}$ & $\begin{array}{l}\mathrm{NO}_{3}^{-} \\
(\mu \mathrm{M})\end{array}$ & $\begin{array}{l}\mathrm{NOx}^{\mathrm{A}} \\
(\mu \mathrm{M})\end{array}$ & & \\
\hline \multicolumn{9}{|c|}{ Control patients } \\
\hline 1 & 0.6 & 36.7 & 37.3 & 0.4 & 33.3 & 33.7 & -3.6 & \\
\hline 2 & 0.4 & 17.9 & 18.3 & 0.4 & 20.2 & 20.6 & 2.3 & \\
\hline 3 & 0.5 & 31.6 & 32.1 & 0.2 & 30.0 & 30.2 & -1.9 & \\
\hline 4 & 0.3 & 22.8 & 23.1 & 0.2 & 19.5 & 19.7 & -3.4 & \\
\hline 5 & 0.1 & 23.1 & 23.2 & 0.1 & 22.9 & 23.0 & -0.2 & \\
\hline 6 & 0.2 & 36.9 & 37.1 & 0.2 & 36.7 & 36.9 & -0.2 & \\
\hline 7 & 0.1 & 35.4 & 35.5 & 0.1 & 33.0 & 33.1 & -2.4 & \\
\hline 8 & 0.1 & 20.5 & 20.6 & 0.1 & 20.1 & 20.2 & -0.4 & \\
\hline 9 & 0.3 & 29.3 & 29.6 & 0.2 & 30.2 & 30.4 & 0.8 & \\
\hline mean \pm SEM & $0.3 \pm 0.1$ & $28.2 \pm 2.5$ & $28.5 \pm 2.5$ & $0.2 \pm 0.0$ & $27.3 \pm 2.2$ & $27.5 \pm 2.2$ & $-1.0 \pm 0.7$ & \\
\hline \multicolumn{9}{|c|}{ Patients with vasospastic angina } \\
\hline 10 & 0.7 & 16.7 & 17.4 & 0.8 & 6.5 & 7.3 & -10.1 & 26 \\
\hline 11 & 0.4 & 20.6 & 21.0 & 0.3 & 12.7 & 13.0 & -8.0 & 30 \\
\hline 12 & 0.4 & 20.6 & 21.0 & 0.5 & 19.1 & 19.6 & -1.4 & 40 \\
\hline 13 & 0.5 & 27.2 & 27.7 & 0.3 & 19.2 & 19.5 & -8.2 & 40 \\
\hline 14 & 0.4 & 21.8 & 22.2 & 0.4 & 22.0 & 22.4 & 0.2 & 50 \\
\hline 15 & 0.3 & 33.5 & 33.8 & 0.3 & 29.6 & 29.9 & -3.9 & 36 \\
\hline 16 & 0.3 & 26.3 & 26.6 & 0.2 & 23.8 & 24.0 & -2.6 & 36 \\
\hline 17 & 0.1 & 20.3 & 30.4 & 0.1 & 18.1 & 18.2 & -2.2 & 38 \\
\hline 18 & 0.2 & 33.2 & 33.4 & 0.2 & 30.4 & 30.6 & -2.8 & 40 \\
\hline mean \pm SEM & $0.4 \pm 0.1$ & $24.4 \pm 2.0$ & $24.8 \pm 2.0$ & $0.3 \pm 0.1$ & $20.2 \pm 2.5^{*}$ & $20.5 \pm 2.5^{*}$ & $-4.3 \pm 1.2^{*}$ & $37 \pm 2$ \\
\hline
\end{tabular}

NOx, nitrite $\left(\mathrm{NO}_{2}^{-}\right)+$nitrate $\left(\mathrm{NO}_{3}^{-}\right)$; $\mathrm{NOx}^{\mathrm{A}}$, NOx level in blood from the ostium of the left coronary artery; $\mathrm{NOx}=\mathrm{NOx}$ level in blood from the coronary sinus; $\mathrm{NOx}$ difference $=\mathrm{NOx}^{\mathrm{V}}-\mathrm{NOx}^{\mathrm{A}} .{ }^{*} p<0.05$ versus control patients. 

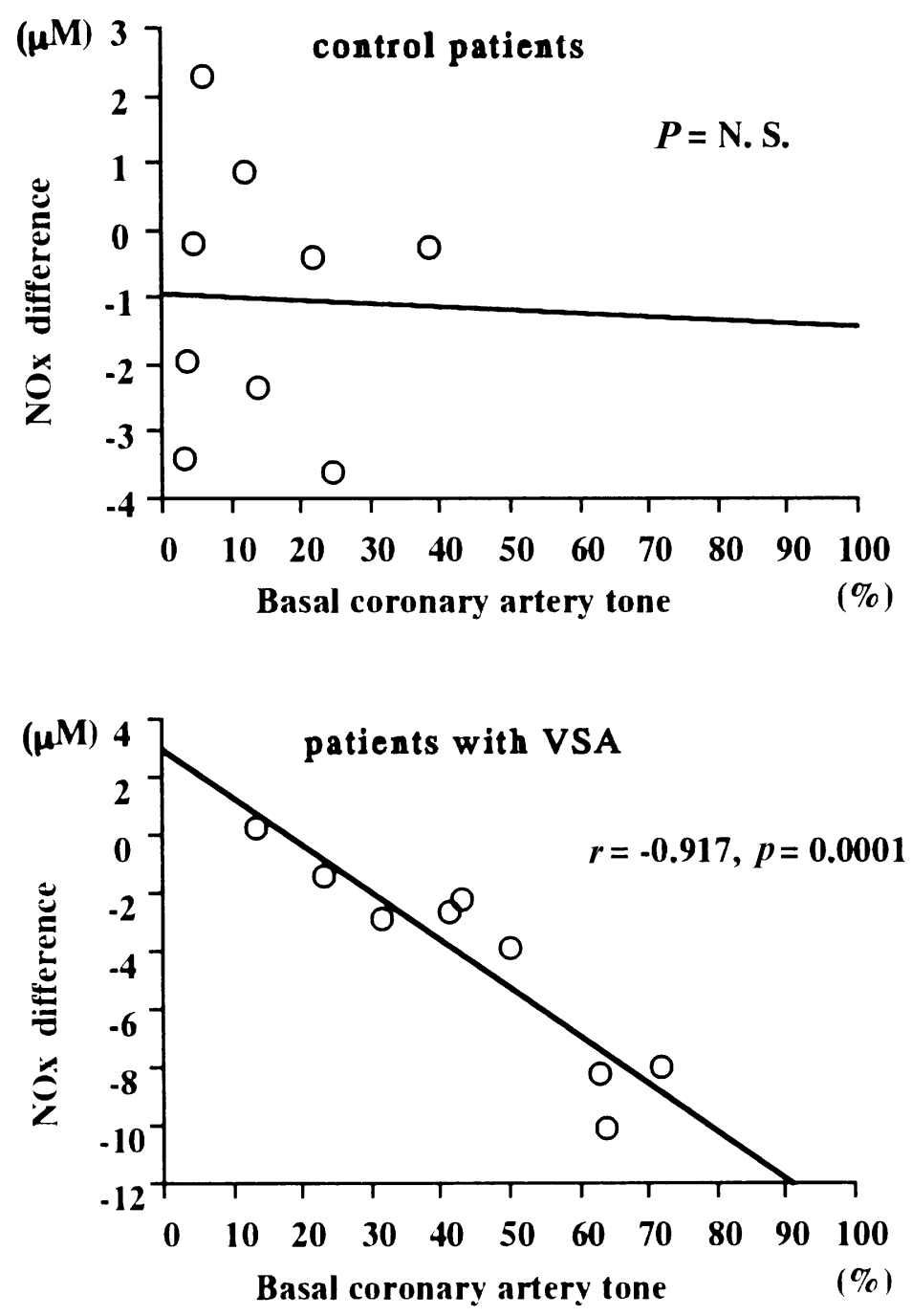

Figure 1. Relation between basal coronary artery tone and NOx difference in control patients (upper panel) and patients with vasospastic angina (lower panel).

ISDN administration, however, all of the coronary artery diameters, including the spastic site, in VSA patients were not statistically different from those in the control patients.

Basal coronary artery tone: Basal coronary artery tone at all segments in VSA patients showed a tendency to be higher than that in control patients (Table III). However, basal coronary tone only at the spastic site in VSA patients was significantly greater than that at the corresponding site in control patients ( $42 \pm 7$ vs $14 \pm 4 \%, p<0.01)$. 


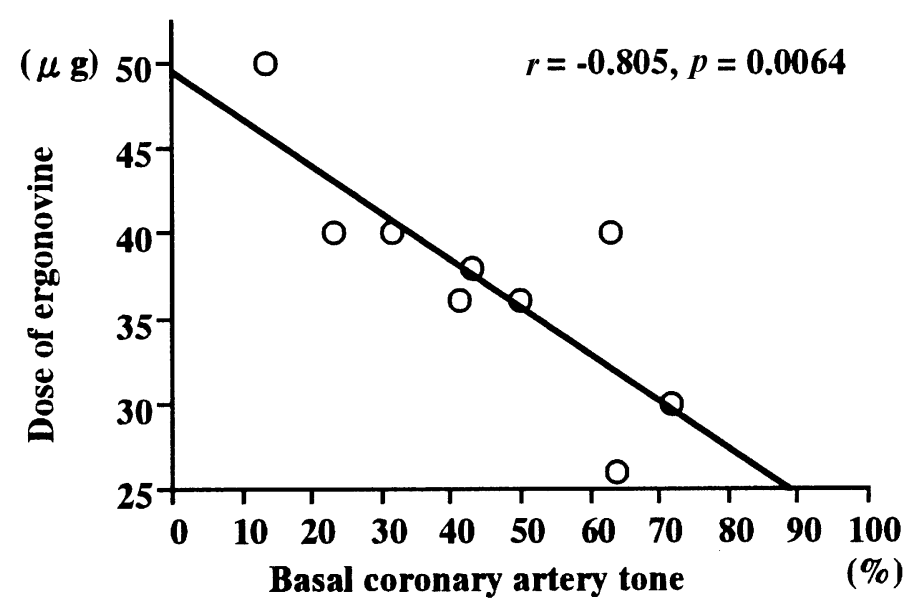

Figure 2. Relation between basal coronary artery tone and ergonovine dose required for spasm provocation in patients with vasospastic angina.

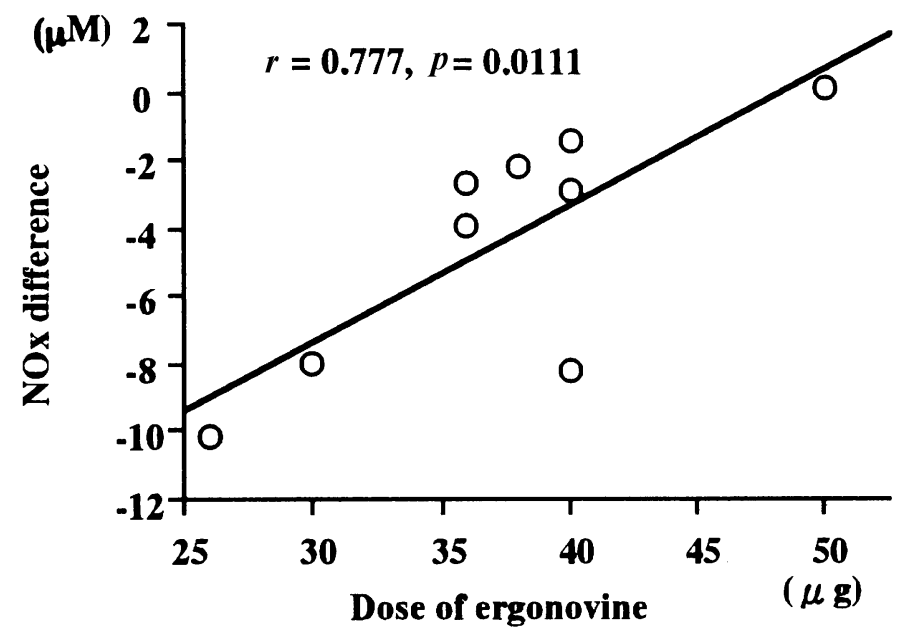

Figure 3. Relation between dose of ergonovine required for spasm provocation and NOx difference in patients with vasospastic angina.

Basal NOx and NOx difference: The baseline levels of plasma $\mathrm{NO}_{2}^{-}$and $\mathrm{NO}_{3}^{-}$in the blood from the ostium of the left coronary artery and those from the coronary sinus are shown in Table IV. The plasma concentration of $\mathrm{NO}_{2}^{-}$was markedly lower than that of $\mathrm{NO}_{3}^{-}$(less than about $2 \%$ ). The baseline $\mathrm{NOx}^{\mathrm{A}}$ values did not differ between the two groups $(24.8 \pm 2.0$ vs $28.5 \pm 2.5 \mu \mathrm{M}, p=\mathrm{NS}$ ) but the baseline $\mathrm{NOx}^{\mathrm{V}}$ values of the VSA patients were lower than those of the control patients $(20.5 \pm 2.5$ vs 27.5 $\pm 2.2 \mu \mathrm{M}, p<0.05)$. The NOx differences of the control patients were 
almost zero but they were apparently negative for patients with VSA. Thus, the VSA patients showed significant NOx imbalance compared to the control patients $(-4.3 \pm 1.2$ vs $-1.0+0.7 \mu \mathrm{M}, p<0.05)$.

Relations between basal coronary artery tone, NOx balance and ergonovine dose:

We observed a significant negative correlation between the basal coronary artery tone and the NOx difference $(r=-0.917, p<0.001)$ for the VSA patients but not for the control patients (Figure 1). In addition, there was a significant negative correlation $(r=-0.80, p<0.01)$ between the VSA patients' basal coronary artery tone at the spastic site and the dose of ergonovine required for spasm provocation (Figure 2). We also observed a significant positive linear relationship between the NOx difference of the VSA patients and the dose of ergonovine required for spasm provocation $(r=0.777, p<0.05)$ (Figure 3$)$.

\section{DISCUSSION}

The major findings of this study are that (1) the NOx difference, in other words the coronary venous-arterial difference in NOx concentration, was negative for the coronary circulation for the VSA patients, (2) there was a significant negative correlation between the basal coronary tone at the spastic site and the NOx difference for the VSA patients, and (3) there was a significant positive correlation between the NOx difference and the dose of ergonovine required for spasm provocation.

There are conflicting opinions concerning NO activity in spastic arteries of VSA patients. ${ }^{14,15)}$ These studies have been examined using LNMMA, however, this inhibitor of NO synthesis has been shown to have a difference in constrictive behavior between the proximal and distal epicardial coronary artery segments. ${ }^{8)}$ Thus, L-NMMA seems to have a limitation on the assessment for the correlation between segmental coronary artery tone and NO activity in the human coronary circulation. In the present study, we directly measured the plasma levels of $\mathrm{NO}_{2}^{-}$and $\mathrm{NO}_{3}^{-}$ with an HPLC-Griess system which functions at a high rate of reliability and a precise quantitative determination. ${ }^{20)}$ Zeballos, et al. ${ }^{21)}$ suggested that a single measurement of venous or arterial plasma level of $\mathrm{NO}_{2}^{-}+$ $\mathrm{NO}_{3}^{-}$, without knowledge of the arterio-venous concentration difference, may not reflect the change in the production of NO. Given that the concentration of nitrate varies greatly in normal individuals, ${ }^{22}$ ) we should interpret the value of NOx with great caution. Therefore, we obtained blood samples from the coronary sinus and the ostium of the left coronary artery to examine the levels of NOx in the coronary circulation in study 
patients.

The baseline levels of plasma $\mathrm{NO}_{2}^{-}$and $\mathrm{NO}_{3}^{-}$are in agreement with previous reports. ${ }^{22,23)}$ The baseline $\mathrm{NOx}^{\mathrm{A}}$ values were not statistically different between the control and VSA patient groups, whereas the baseline $\mathrm{NOx}^{\mathrm{V}}$ values of the VSA patients were significantly lower than those of the control patients. Furthermore, the NOx difference of the control patients was close to zero while that of the VSA patients was clearly negative. This result indicates that a decreased NOx level in the coronary circulation is a meaningful reflection in the pathophysiological condition of VSA patients. The precise mechanism of this decrease in NOx level remains unknown although there are three possible explanations: (1) a decrease in NO production in the coronary circulation, (2) increased degradation of $\mathrm{NO}$ to inactive metabolites, before it acts on the smooth muscle and (3) increased elimination or uptake of $\mathrm{NO}, \mathrm{NO}_{2}^{-}$or $\mathrm{NO}_{3}^{-}$via a metabolic pathway such as conversion to urea within the coronary circulation. $^{22)}$

Although there is a possibility of reduced NO production from endothelial cells of the coronary arteries in VSA patients, ${ }^{14)}$ it would not be sufficient to interpret the negative NOx difference. Even if the NO release is completely suppressed within the entire coronary tree as well as the spasm arteries, the NOx difference would be zero at most. Therefore, the disappearance of $\mathrm{NO}, \mathrm{NO}_{2}^{-}$or $\mathrm{NO}_{3}^{-}$through the coronary circulation, besides reduced NO production, should be taken into consideration for the negative NOx difference in VSA patients. It has been recently shown that oxygen-derived free radicals may partly play a role in the abnormal coronary vasomotor reactivity and anginal attack in patients with VSA. ${ }^{24,25)}$ Although the oxygen-derived free radicals generated in the coronary circulation were not investigated in the present study, our observation suggests that there is a possibility of an increased breakdown of NO by oxygen radicals within the coronary circulation. $\mathrm{NO}$ is considered to be rapidly oxidized by oxyhemoglobin, molecular oxygen and superoxide anions in vivo. ${ }^{22,26)}$ Moreover, many studies ${ }^{27-29)}$ indicate that oxidized lipoproteins and low density lipoproteins enhance the inactivation of NO to peroxynitrite by the reaction with superoxide formed by endothelium. Kugiyama, et al. ${ }^{24)}$ recently demonstrated higher basal generation of lipid peroxidation in the human coronary circulation in VSA patients than in control patients during intracoronary infusion of acetylcholine. Therefore, these results seem to be consistent with the explanation that the increased breakdown of NO within the coronary circulation can be one of the probable mechanisms for the negative NOx difference in the coronary circu- 
lation in VSA patients. In fact, the negative NO difference in the coronary circulation was observed in some pathophysiological conditions although the mechanism may be different for each condition. Recchia, et al. ${ }^{30}$ recently demonstrated that a negative NO difference in the coronary circulation was observed in dogs with decompensated heart failure. We also showed that a negative NOx difference in the coronary circulation may reflect endothelial dysfunction in patients with severe coronary stenosis. ${ }^{20}$

Previous studies have shown that basal coronary tone is elevated at spastic sites in VSA patients ${ }^{12,13)}$ and that there is supersensitivity of the dilator effect of nitrovasodilators in the coronary arteries of patients with VSA. ${ }^{31-33)}$ Our results are in agreement with these previous studies, and may be persuasive findings to explain the increased basal coronary tone in patients with VSA and the hyperreactivity to nitrovasodilators not only at a localized segment but also in the entire coronary tree in VSA patients. In our study, although the significantly higher basal coronary tone was recognized only at the spastic site, there was a tendency for the basal coronary tone to be diffusely increased in all segments of the left coronary arteries in VSA patients. Moreover, there was a strong negative correlation between the basal tone at the spastic site and the NOx difference in the coronary circulation. Thus, we believe that the diffusely increased coronary tone may be mainly due to the decrease in NOx in the coronary circulation in VSA patients and that the particularly increased basal tone of the spastic segments may be more clearly reflected in this decrease in NOx. However, this decrease in NOx may not be the sole cause of coronary vasospasm because patients with atherosclerosis impaired endothelial NO release are not necessarily associated with coronary vasospasm. In fact, Toyo-oka, et al. ${ }^{34)}$ reported the contribution of plasma levels of endothelin-1 during the coronary circulation in patients with VSA.

There is considerable interest in the relationship between coronary vasospasm and coronary artery tone on the one hand and endogenous NO level in coronary circulation on the other. As previously reported, ${ }^{12,35)}$ the dose of ergonovine required for provocation of spasm differed among patients with VSA, and there was a significant negative correlation between the basal coronary artery tone of the spastic site and the dose of ergonovine required for spasm provocation in our study. Furthermore, the present study demonstrated that there is a significant positive linear relation between the dose of ergonovine required for spasm provocation and the NOx difference in patients with VSA. Therefore, we postulate that a decrease in the amount of NO available to cause vasorelaxation is an underlying mechanism that elevates basal coronary artery tone by making 
smooth muscle susceptible to vasospastic stimuli (e.g. ergonovine) in patients with VSA.

Conclusion: In conclusion, our patients with VSA showed a negative NOx difference in the coronary circulation, which was closely related to the elevated basal tone of the spastic coronary artery, and which may play an important role in the pathophysiological mechanism of coronary vasospasm. Further studies are required to elucidate the precise mechanism of the decrease in the NOx difference in the coronary circulation of VSA patients.

\section{ACKNOWLEDGMENT}

This work was supported in part by a Research Grant for Cardiovascular Disease (10C-5) from the Ministry of Health and Welfare of Japan and a Grant for Project Research from Kanazawa Medical University (P98-6).

\section{REFERENCES}

1. Bassenge E, Busse R. Endothelial modulation of coronary tone. Prog Cardiovasc Dis 1988; 30: 340-80.

2. Luscher TF, Richard V, Tschudi M, Yang Z, Boulanger C. Endothelial control of vascular tone in large and small coronary arteries. J Am Coll Cardiol 1990; 15: 512-27.

3. Moncada S, Higgs A. The L-arginine-nitric oxide pathway. N Engl J Med 1993; 329: 2002-12.

4. Palmer RM, Ferrige AG, Moncada S. Nitric oxide release accounts for the biological activity of endotheliumderived relaxing factor. Nature 1987; 327: 524-6.

5. Palmer RM, Ashton DS, Moncada S. Vascular endothelial cells synthesize nitric oxide from L-arginine. Nature 1988; 333: 664-6.

6. Chu A, Chambers DE, Lin C, et al. Effects of inhibition of nitric oxide formation on basal vasomotion and endothelium-dependent responses of the coronary arteries in awake dogs. J Clin Invest 1991; 87: 1964-8.

7. Vallance P, Collier J, Moncada, S. Effects of endothelium-derived nitric oxide on peripheral arteriolar tone in man. Lancet 1989; 2: 997-1000.

8. Lefroy DC, Crake T, Uren NG, Davies GJ, Maseri A. Effects of inhibition of nitric oxide synthesis on epicardial artery caliber and coronary blood flow in humans. Circulation 1993; 88: 43-54.

9. Quyyumi AA, Dakak N, Andrews NP, et al. Nitric oxide activity in the human coronary circulation: impact of risk factors for coronary atherosclerosis. J Clin Invest 1995; 95: 1747-55.

10. Kuga T, Egashira K, Mohri M, et al. Bradykinin-induced vasodilation is impaired at the atherosclerotic site but is preserved at the spastic site of human coronary artery in vivo. Circulation 1995; 92: 183-9.

11. Hill JA, Feldman RL, Pepine CJ, Conti CR. Regional coronary artery dilation response in variant angina. Am Heart J 1982; 104: 226-33.

12. Kuga T, Egashira K, Iou T, Takeshita A. Correlation of basal coronary artery tone with constrictive response to ergonovine in patients with variant angina. J Am Coll Cardiol 1993; 22: 144-50.

13. Hoshino A, Kotake H, Mashiba H. Significance of coronary artery tone in patients with variant angina. J Am Coll Cardiol 1989; 14: 604-9.

14. Kugiyama K, Yasue H, Okumura K, et al. Nitric oxide activity is deficient in spasm arteries of patients with coronary spastic angina. Circulation 1996; 94: 266-72.

15. Egashira K, Katsuda Y, Mohri M, et al. Basal release of endothelium-derived nitric oxide at site of spasm in patients with variant angina. J Am Coll Cardiol 1996; 27: 1444-9. 
16. Matsubara T, Tamura Y, Yamazoe M, et al. Correlation between arteriographic and electrocardiographic features during spasm in the left anterior descending coronary artery. Coronary Artery Dis 1997; 8: 525-35.

17. Igarashi Y, Yamazoe M, Shibata A. Effect of direct intracoronary administration of methylergonovine in patients with and without variant angina. Am Heart J 1991; 121: 1094-100.

18. Arima T, Ohshima Y, Mizuno T, Kitamura Y, Segawa T, Nomura Y. Cyclic GMP elevation by 5-hydroxytryptamine is due to nitric oxide derived from endogenous nitrosothiol in NG108-15 cells. Biochem Biophys Res Commun 1996; 227: 473-8.

19. Yamada K, Nabeshima T. Simultaneous measurement of nitrite and nitrate levels as indices of nitric oxide release in the cerebellum of conscious rats. J Neurochem 1997; 68: 1234-43.

20. Ishibashi T, Matsubara T, Ida T, et al. Negative $\mathrm{NO}_{3}{ }^{-}$difference in human coronary circulation with severe atherosclerotic stenosis. Life Sciences 2000; 66: 173-84.

21. Zeballos GA, Bernstein RD, Thompson CI, et al. Pharmacodynamics of plasma nitrate/nitrite as an indication of nitric oxide formation in conscious dogs. Circulation 1995; 91: 2982-8.

22. Wennmalm Ake, Benthin G, Edlund A, et al. Metabolism and excretion of nitric oxide in humans. Circ Res. 1993; 73: 1121-7.

23. Node K, Kitakaze M, Sato H, et al. Increased release of nitric oxide in ischemic hearts after exercise in patients with effort angina. J Am Coll Cardiol 1998; 32: 63-8.

24. Kugiyama K, Motoyama T, Hirashima O, et al. Vitamin C attenuates abnormal vasomotor reactivity in spasm coronary arteries in patients with coronary spastic angina. J Am Coll Cardiol 1998; 32: 103-9.

25. Miwa K, Miyagi Y, Igawa A, Nakagawa K, Inoue H. Vitamin E deficiency in variant angina. Circulation 1996; 94: 14-8.

26. Beckman JS, Koppenol WH. Nitric oxide, superoxide, and peroxynitrite: the good, the bad, and the ugly. Am J Physiol 1996; 271: C1424-37.

27. Tanner FC, Noll G, Boulanger CM, Luscher TF. Oxidized low density lipoproteins inhibit relaxations of porcine coronary arteries. Role of scavenger receptor and endothelium-derived nitric oxide. Circulation 1991; 83: 2012-20.

28. Chin JH, Azhar S, Hoffman BB. Inactivation of endothelial derived relaxing factor by oxidized lipoproteins. J Clin Invest 1992; 89: 10-8.

29. Galle J, Bengen J, Schollmeyer P, Wanner C. Impairment of endothelium-dependent dilation in rabbits renal arteries by oxidized lipoprotein (a). Role of oxygen-derived radicals. Circulation 1995; 92: 1582-9.

30. Recchia FA, McConnell PI, Bernstein RD, Vogel TR, Xu X, Hinze TH. Reduced nitric oxide production and altered myocardial metabolism during the decompensation of pacing-induced heart failure in the conscious dog. Circ Res 1998; 83: 969-79.

31. Yasue H, Omote S, Takizawa A, Nagano M. Coronary arterial spasm in ischemic heart disease and its pathogenesis. Circ Res 1983; 52 (suppl. I) : 147-52.

32. Okumura K, Yasue H, Matsuyama K, et al. Diffuse disorder of coronary artery vasomotility in patients with coronary spastic angina. Hyperreactivity to the constrictor effects of acetylcholine and the dilator effects of nitroglycerin. J Am Coll Cardiol 1996; 2745-52.

33. Kugiyama K, Ohgushi M, Sugiyama S, et al. Supersensitive dilator response to nitroglycerin but not to atrial natriuretic peptide in spastic coronary arteries in coronary spastic angina. Am J Cardiol 1997; 79: 606-10.

34. Toyo-oka T, Aizawa T, Suzuki N, et al. Increased plasma level of endothelin-1 and coronary spasm induction in patients with vasospastic angina pectoris. Circulation 1991; 83: 476-83.

35. Matsuda Y, Moritani $\mathrm{K}$, Ogawa $\mathrm{H}$, et al. Response of the coronary artery to a small dose of ergonovine in variant angina. Am Heart J 1986; 112: 947-52. 